\title{
Effect of Nanoparticles Shape on the Efficiency of Hybrid Solar Cells
}

\author{
Mirela-Ionela MIHAI ${ }^{1}$, Ruxandra VIDU ${ }^{2 *}$, Adrian BADEA ${ }^{1}$ \\ ${ }^{1}$ University Politehnica Bucharest Romania, \\ ${ }^{2}$ University of California Davis, Dept. Material Science and Engineering, United State \\ *Corresponding author: rvidu@ucdavis.edu
}

\begin{abstract}
In recent years, the solar cell research interest has been focused on hybrid solar cells that use the advantage of mixed active layer such as semiconductor nanoparticles and polymeric organic materials. The goal of the solar research groups is to increase the efficiency of solar cells, their lifetime and cost of fabrication. For example, the solar cells based on silicon has long lifetime, good efficiency, but high fabrication costs. Solar market shows a great interest in hybrid solar cells due to their increased yield, extended lifetime compared to organic cells, and ease in fabrication with great potential in reducing the manufacturing costs. In this paper, the effect of various nanostructures on the performance of hybrid solar cells was studied. A relationship between the nanoparticle shapes and solar cell efficiency was developed, which showed that the aspect ratio of nanoparticles was an important factor in designing solar cells with improved efficiency.
\end{abstract}

\section{Introduction}

The energy demand increases each year. This growth has imposed an increase in both energy production from conventional sources and development of new technologies. Additionally, the global warming caused by the increase in $\mathrm{CO}_{2}$ concentration [1] has forced the legislative to take action and promote the research and development of the technologies in renewable energy. Solar energy is one of the greatest renewable energy sources because Earth receives from the sun enough energy each hour to meet all the energy needs around the world in a year. Currently, photovoltaic (PV) cells provide only $0.04 \%$ of the total energy produced per year from all the energy sources [1].

The European Renewable Energy Council (EREC) estimates that the renewable energy will increase up to $50 \%$ by 2040 [2]. This ambitious target challenges and creates competitive markets for solar energy research and requires a high scale solar energy deployment. Presently, the renewable energy source contributes with $20 \%$ at the global level of total energy consumption, while the rest of $80 \%$ comes from primary energy sources. For instance, in the 2013 calendar year, the total power output of photovoltaic panel (PV) in the world was around 160 billion $\mathrm{kW} / \mathrm{h}$, which means about $0.85 \%$ of the total energy demand in the world [3]. The European Photovoltaic Association (EPIA) estimated that the global PV production will increase up to approximately 2,646 TWh/year by year 2030. Table 1 presents the statistics of the renewable energies including the estimated values by the year of 2040 [2].

Data presented in Table 1 predicts that the renewable energy based on PV in the year 2040 will increase up to $13 \%$. Researchers are working to create PV cells with high light absorption, high conversion efficiency, and extended life cycle [4]. Presently, the best performing solar cells are multijunction solar cells that reached $44.7 \%$. Among single junction solar cells, the best performing are the solar cells based on $\mathrm{Si}$, followed by thin film cells and hybrid and organic cells [4]. Organic solar cell (OPV) is a type of cell that is based on conductive organic polymers or small organic molecules designed to capture the light absorption to produce electricity. The OPV were discovered in 1987 and their efficiency was just $2.1 \%$ [5]. In 2000 , the research work on OPV escalated due to their high potential of large mass production at a low cost. OPVs can be produced using inexpensive technologies such as roll-to-roll processes, where the layers were printed on a flexible substrate. 
Moreover, materials used in the OPV fabrication are not toxic [5]. The OPV are now in the competition for a market share, reaching an efficiency of $12 \%$ in 2013 [6]. The "Heliatek" company alleged that the efficiency of organic solar cells is estimated to reach $15 \%$ [6].

Table1. Statistics and predictions of renewable energy technologies based on the "Renewable Energy Scenario to 2040", by the European Renewable Energy Council (EREC) [2]:

\begin{tabular}{|c|c|c|c|c|c|}
\hline Years & $\begin{array}{c}1996 \\
- \\
2001\end{array}$ & $\begin{array}{c}2001 \\
- \\
2010\end{array}$ & $\begin{array}{c}2010 \\
- \\
2020\end{array}$ & $\begin{array}{c}2020 \\
- \\
2030\end{array}$ & $\begin{array}{c}2030 \\
- \\
2040\end{array}$ \\
\hline Biomass & $2 \%$ & $\begin{array}{c}2.20 \\
\%\end{array}$ & $\begin{array}{c}3.10 \\
\%\end{array}$ & $\begin{array}{c}3.30 \\
\%\end{array}$ & $\begin{array}{c}2.80 \\
\%\end{array}$ \\
\hline $\begin{array}{l}\text { Large } \\
\text { hydro }\end{array}$ & $2 \%$ & $2 \%$ & $1 \%$ & $1 \%$ & $0 \%$ \\
\hline $\begin{array}{l}\text { Small } \\
\text { hydro }\end{array}$ & $6 \%$ & $8 \%$ & $10 \%$ & $8 \%$ & $6 \%$ \\
\hline Wind & $33 \%$ & $28 \%$ & $20 \%$ & $7 \%$ & $2 \%$ \\
\hline PV & $25 \%$ & $28 \%$ & $30 \%$ & $25 \%$ & $13 \%$ \\
\hline $\begin{array}{c}\text { Solar } \\
\text { thermal }\end{array}$ & $10 \%$ & $16 \%$ & $16 \%$ & $14 \%$ & $7 \%$ \\
\hline $\begin{array}{c}\text { Solar } \\
\text { thermal } \\
\text { electricity }\end{array}$ & $2 \%$ & $16 \%$ & $22 \%$ & $18 \%$ & $15 \%$ \\
\hline Geothermal & $6 \%$ & $8 \%$ & $8 \%$ & $6 \%$ & $4 \%$ \\
\hline $\begin{array}{c}\text { Marine } \\
\text { (tidal/wave/ } \\
\text { ocean) }\end{array}$ & & $8 \%$ & $15 \%$ & $22 \%$ & $21 \%$ \\
\hline
\end{tabular}

Then, dye-sensitized solar cell with an efficiency of $11-12 \%$ has been developed, followed by the tandem organic solar cells, inorganic solar cells and quantum-dots (QDs). In 2010, the National Renewable Energy Laboratory (NREL) researchers have improved efficiency and performance of the solar cells containing PbS QDs, by adding metal oxides such as: molybden oxide $\left(\mathrm{MoO}_{\mathrm{x}}\right)$, vanadium oxide $\left(\mathrm{V}_{2} \mathrm{O}_{\mathrm{x}}\right)$ in the active layer of the solar cell to improve heterojunction solar cell consisting of $\mathrm{ZnO} / \mathrm{PbS}$ [7]. The efficiency of the cell has reached $4.4 \%$. In 2011, University of Toronto obtained a solar cell based on $\mathrm{PbS}$ colloidal quantum dots (CQDs) mixed with organic ligand with an efficiency rate of $6 \%$ (AM 1.5 conditions) [8].

The solar research community continue to search for ways to improve solar cell efficiency while keeping the cost low to fabrication. Hybrid solar cells (HSC) were developed to combine the high efficiency of thin films with the ease of fabrication of organic cells. This paper presents a study of the nanoparticle structure and size used in HSC, based on the most recent developments in the HSC technologies. In the study of HCS performance, both the nanoparticle synthesis methods and the shape and the size of nanoparticles are discussed.

\section{Hybrid solar cells}

Hybrid solar cells (HSCs) are a potential candidate for commercial PVs due to their fast optical absorption, ease of fabrication, low production costs, and a favorable combination of organic and inorganic semiconductors [9]. HSC has an active layer composed of a blend of organic materials such as polymers and inorganic nanoparticles, which improve the absorption of light and enhance the electrons transport from cell to collector [1]. These cells typically consist of a glass substrate, transparent conductive oxide layer (ITO), poly (3, 4-ethylenedioxythiophene) PDOT:PSS, nanoparticles, polymer blend and a metal cathode as shown in Figure 1.

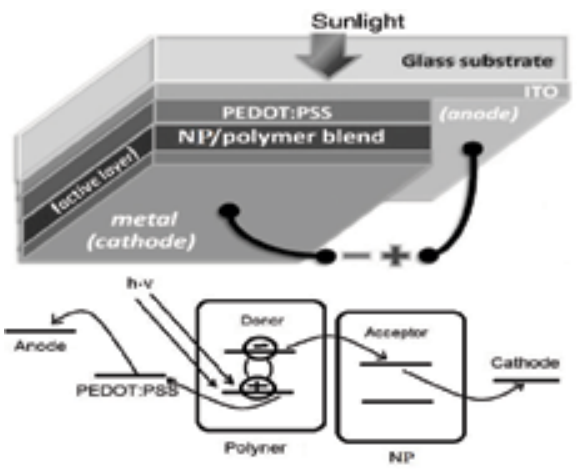

Figure 1. Schematic representation of HSC device (top) and solar cells works to collect the electron (bottom). 
The PDOT:PSS polymeric blend forms a layer that helps the transport of electrons to anode.

A critical detail in the composition of HSC is represented by the diversity of shapes of nanoparticle that may be used. A certain shape of nanoparticles may increase the efficiency and the performance of hybrid solar cells but there is no direct relationship demonstrated for them. For example, Lazaro A. et al [10] investigated the role of the PbSe nanostructure shape by comparing elongated and spherical quantum dots (QD) nanoparticles. They found out that the high aspect ratio of elongated particles increases the efficiency of light absorption compared to spherical (dot) nanoparticles [10].

There is a vast diversity of shapes and sizes of nanoparticles that may have a direct and critical impact on the performance of hybrid solar cells. In addition, the efficiency of HSC is influenced by the $\mathrm{NP}$ synthesis method as well as device fabrication technique.

\section{Nanoparticle for HSC and their Synthesis Methods}

\section{1. $\mathrm{CuInS}_{2}$ (CIS) nanocrystals}

Colloidal synthesis was used to fabricate dispersed particles suspended in a liquid medium. Although it is difficult to control the morphology of semiconductor nanostructures, tailored nanocrystals can be produced by simply changing the synthesis parameters (i.e. reaction time and temperature). In the case of $\mathrm{CuInS}_{2}$ colloidal synthesis, $\mathrm{CuInS}_{2}$ and oleylamine, trioctylphosphine oxide (TOPO), was injected in a mixture by 1-dodecanethiol, tert-dodecanethiol [11]. This solution was maintained at $240{ }^{\circ} \mathrm{C}$, resulting in the formation of elongated CIS nanoparticles that had approximately uniform size distribution. Oleylamine acts as a solvent, but also as monomer to stabilize the particles. The nanoparticles have a diameter of $19.1 \mathrm{~nm}$ and a length of about $44.8 \mathrm{~nm}$. Transmission Electron Microscope (TEM) analysis was used to study the growth mechanism of CIS nanocrystal during chemical reaction. It was observed that 75 seconds after injection, nanoparticles size increased, resulting in a squarelike shape (Figure 2). After 80 seconds, the CIS particles reached an elongated shape, which then increased along the (002) axis and had an orientations perpendicular to the axis (100) [11].

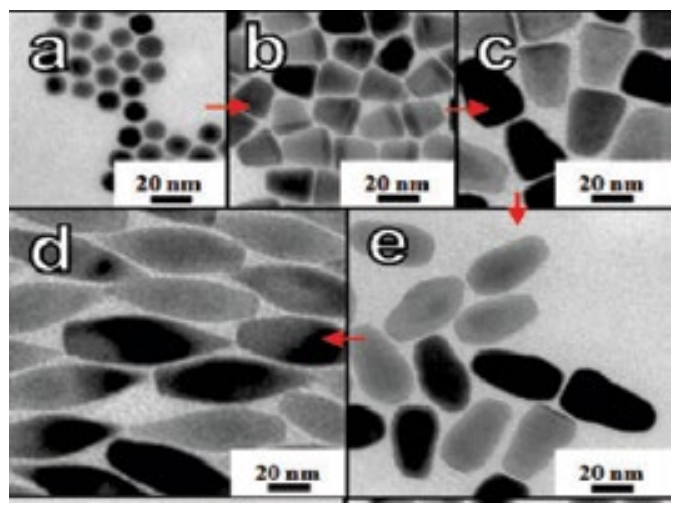

Figure 2. TEM of CIS(CuInS 2$) \mathrm{NP}$ [11]: a) $\mathrm{Cu}_{2} \mathrm{~S}$ particles before the reaction; $b$-d) particles of $\mathrm{Cu}$ : In, in ratio $1: 1$ during synthesis after $75 \mathrm{~s}(\mathrm{c}), 80 \mathrm{~s}(\mathrm{e})$ and $90 \mathrm{~s}(\mathrm{~d})$ particles has a perfect elongated shape [11].

CIS elongated shape had an optical absorption between $400 \mathrm{~nm}$ and $900 \mathrm{~nm}$. Because of the versatility in shape induced by synthesis process (Figure 2), CIS nanoparticles were used as thin films and hybrid devices in solar cells research.

\subsection{CdSe Nanoparticles}

CdSe nanocrystal: Brandeburg et al. [12] have synthesysed $\mathrm{CdSe}$ nanoparticles by colloidal method. The HSC device was fabricated on ITO substrate, where a PEDOT: PSS layer was applied by spin-coting. Subsequently, an active layer made of CdSe: P3HT was applied and treated at $140{ }^{\circ} \mathrm{C}$ for $10 \mathrm{~min}$. An $\mathrm{Al}$ layer deposited by evaporation was used as a cathode [12]. The size of CdSe nanoparticles was $2.3-10 \mathrm{~nm}$ and the wavelength was between $400 \mathrm{~nm}$ to $600 \mathrm{~nm}$. The efficiency of the device was $0.45 \%$ [12].

CdSe nanorods: Farva et al. [13] obtained CdSe nanorods with controlled size and shape using a slightly modified hot-injection method. After synthesis, CdSe nanorods were annealed at $350{ }^{\circ} \mathrm{C}$ for 30 minutes to investigate the influence of air annealing process on the structural and optical properties of nanorods [13]. During annealing, the nanorod size increased from 4-5 nm to $10-12 \mathrm{~nm}$ in diameter, and from about $20 \mathrm{~nm}$ to $23-25 \mathrm{~nm}$ in length. Additionally, the heat treatment influenced the photoluminescence (PL) spectra due to 
improved crystallinity after annealing. PL emission peak shifted after annealing from $625 \mathrm{~nm}(1.98 \mathrm{eV})$ to $628 \mathrm{~nm}$ (red shift) [13].

CdSe tetrapod: Complex nanowire structures that form both hierarchical branches and multicomponent heterostructures of engineered material combinations, are likely to be used in harvesting and conversion of solar energy. Nanoparticles with tetrapod shapes were obtained for semiconductors of groups II and VI [14]. CdSe nanoparticles with tetrapod shapes can be obtained by chemical synthesis, because the form of nanocrystals (NCs) can be controlled by varying synthesis parameters. Manna et al. [14] obtained tetrapod shapes from CdSe nanocrystals seeds of $10-15 \mathrm{~nm}$ in size (Figure 3). This 3D shape has an important role in electron transport, because the three arms of the tetrapod are anchored in the cathode, and the fourth arm is directed upwards, reaching the active layer. Additionally, CdSe with a tetrapod shape has a good optical absorption of light, which can be exploited in hybrid solar cells [1]. For instance, the PCE for a cell made of CdSe tetrapod, pyridinecapped and PCTDTBT polymer was about $3.19 \%$, with an external quantum efficiency (EQE) of $55 \%$, and a wavelength of $630-720 \mathrm{~nm}$ [1].
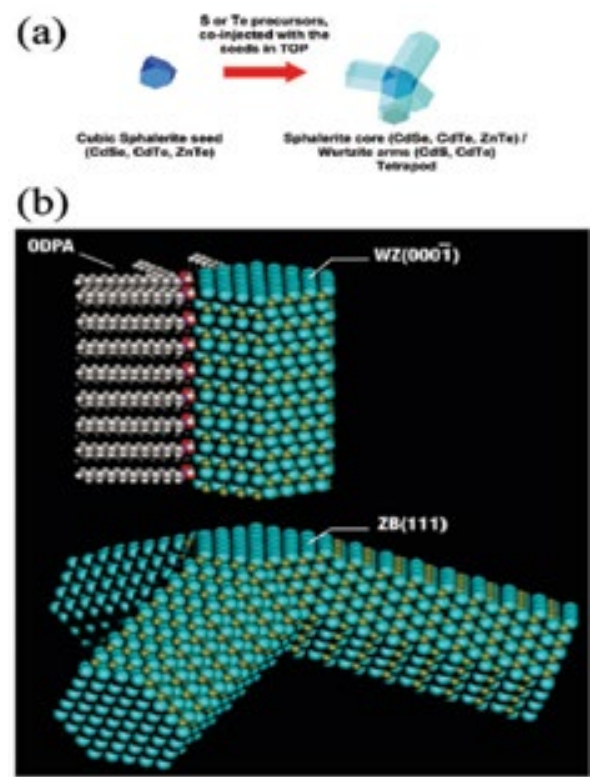

Figure 3. Illustration of tetrapod structure obtained by seeded growth method $[1,22]$.
Similar to CdSe tetrapod, $\mathrm{ZnO}$ tetrapods called "fourlings" were obtained in vapor phase [15]. In this case, polycrystalline $\mathrm{ZnO}$ nucleus led to twinning mechanism. This formation mechanism involves stacking fault between the central nucleus and each branch [15].

\section{3. $\mathrm{TiO}_{2}$ Nanoparticles}

$\underline{T i O}_{2}$ crystalline nanoparticles: $\mathrm{TiO}_{2}$ rods are generally used in HSC due to their low cost and good power conversion efficiency (PCE) of about 4\%. Guttmann et al. [16] obtained crystalline $\mathrm{TiO}_{2}$ nanoparticles for a HSC. This device contained solar cells that are made of $\mathrm{FTO} / \mathrm{TiO}_{2} \mathrm{rod} / \mathrm{blend} /$ PEDOT: PSS/Au [16], where the active layer consisted of $\mathrm{TiO}_{2}$ rods embebed in P3HT polymer. Figure 4 shows $\mathrm{TiO}_{2}$ crystalline rods with a diameter to length ratio of 1 to 10 , which were obtained from $\mathrm{TiCl}_{4}$ precursor. The solar cell based on the polymeric $\mathrm{TiO}_{2}$ active blend was tested under 1.5 AM conditions. The HSC had an efficiency of $0.13 \%$ and filling factor of $31 \%$ [16].

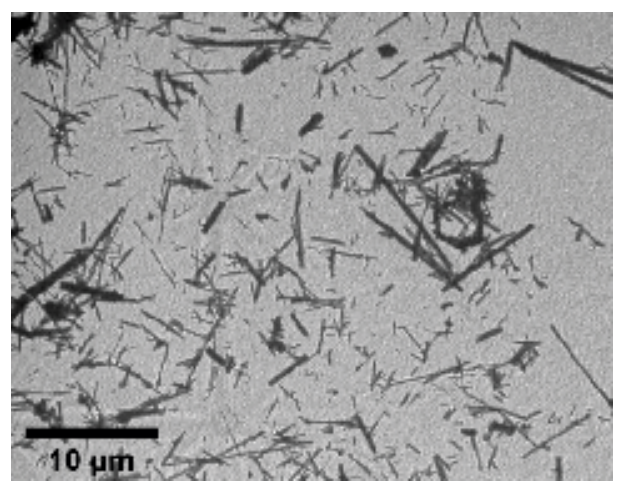

Figure 4. TEM image of $\mathrm{TiO}_{2}$ rods [16].

$\underline{T i O}_{2}$ nanorods: Hybrid solar cells based on $\mathrm{TiO}_{2}$ nanorods with a diameter size between $(7 \pm 1) \mathrm{nm}$ and $(19 \pm 3) \mathrm{nm}$ [24] were synthesis by nonhydrolytic methods. $\mathrm{TiO}_{2}$ nanorods have quantum efficiencies of up to $15 \%$ measured at AM 1.5. The solar PCE was $\eta=0.49 \%$. These nanoparticles, are not toxic and they have a good physical and chemical stability. $\mathrm{TiO}_{2}$-based $\mathrm{HSC}$ was made using ITO/PEDOT: PSS/blend/Al. This blend was formed by $\mathrm{TiO}_{2}$ nanorod and P3HT. After annealing, an improved yield of separation charge was observed. $\mathrm{TiO}_{2}$ nanorod has an important role in blend by forming traps to capture photon. After 
annealing, the device tested in AM 1.5 spectrum, $50 \mathrm{MW} / \mathrm{cm}^{-2}$ had a PCE by $\eta=0.49 \%$ [24].

$\underline{\text { TiO }}_{2}$ nanoparticles: Typically, the main method for producing metal oxide nanoparticles is the solgel process. This process starts with a colloidal solution (sol) which acts as a precursor for the gel [17]. In fact, the sol is a solution that contains colloidal particles (inorganic or organic) suspended in a liquid. For instance, $\mathrm{TiO}_{2}$ colloidal nanoparticles can be obtained from a solution containing a mixture of ethanolamine (TEOA), ethoxide (TEO) and distilled water at room temperature, to which $\mathrm{NaOH}$ solution is added to adjust for $\mathrm{pH}$. Then, an amine such as tridodecylamine (TDA) is added. The solution is placed in Teflon-lined container for $24 \mathrm{~h}$ at 100 ; then the temperature is increased to $140{ }^{\circ} \mathrm{C}$ and kept for 72 $\mathrm{h}$. This process helps the nucleation and growth of $\mathrm{TiO}_{2}$ nanoparticles [18]. $\quad \mathrm{TiO}_{2}$ nanoparticles obtained by sol-gel have elongate shape, with a diameter of $30-40 \mathrm{~nm}$ and length of $15-30 \mathrm{~nm}$. When these $\mathrm{TiO}_{2}$ nanoparticles were used in DSSC, the efficiency was $5.04 \%$ with a filling factor (FF) of $0.45 \%$ [18].

\subsection{Quantum Dot (QD) structures: PbSe- QD, CdSe colloidal QDs, CdSeS-QD, etc.}

Quantum Dot (QD) are mainly used in DSSC due to their good absorption power (about 12\% [19, 20]) and inexpensive manufacture costs. For example, electrophoretic deposition is a process of depositing layers on a substrate/electrode, from a solution that contains nanoparticles/QDs under an applied electric field [14]. In solvents such as toluene and acetonitrile, QDs are negatively charged, which means that QDs will be attracted to the positive electrode. Electrode materials used in HSC are mesoscopic oxide $\mathrm{TiO}_{2}, \mathrm{ZnO}, \mathrm{SnO}_{2}$, and $\mathrm{Nb}_{2} \mathrm{O}_{5}$ [15], used as thin films of 5 to $10 \mu \mathrm{m}$ thickness over optically transparent electrodes. There are several methods of making QD films [14-16], as shown in Figure 5.

Several QDs material systems have been studied for their possible adoption in HSC. An example of QD which are often used in HSC is PbSe quantum dot PEDOT: PSS layers [21]. The PbSe QDs have been obtained with a diameter of $4.5 \mathrm{~nm}$. The HSC had a filling factor (FF) of $45.5 \%$, but low efficiency. W. Zou et al. [22] has synthesized colloidal CdSe QDs with oleic acid ligand. The
CdSe QDs had diameters between 3.1 and $3.9 \mathrm{~nm}$ with a deviations $\pm 0.2 \mathrm{~nm}$, and an optical absorption spectral of about $450 \mathrm{~nm}$. Kumari et al. [23] have demonstrated that CdSe QDs $(5 \sim 7 \mathrm{~nm})$ with TOPO and oleic acid (OA) have a good surface passivation and optoelectronic properties.

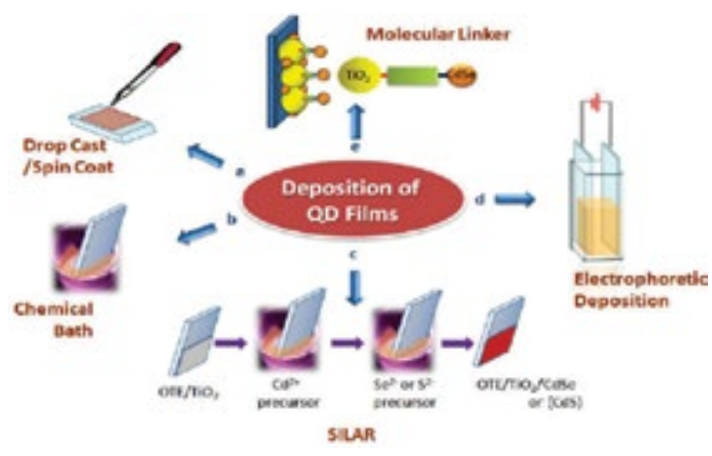

Figure 5. Schematic illustration of deposition of QD films obtained by the method presented in Ref [11]: a) drop cast/spin coat, b) chemical bath, c) SILAR, d) electrophoretic deposition; e) molecular linker.

The CdSe (TOPO) QDs had an absorption of wavelength between $493 \mathrm{~nm}$ to $506 \mathrm{~nm}$. However, the efficiency of the HSC device made with CdSe (TOPO) QDs was very low. For example, $\mathrm{CdS} / \mathrm{CdSe} \mathrm{QDs}$ were doped with Mn to improve electrical properties and light absorption through wavelength control [20]. The efficiency conversion for an incident photon in $\mathrm{Mn}$ - doped $\mathrm{CdS} / \mathrm{CdSe}$ increased to $68 \%$ and $80 \%$. Using a molecular linker is another method to improve the performance of QDs/ DSSC, through inverted $\mathrm{CdS} / \mathrm{CdSe}$ QDs, using organometallics at high temperature, and then synthesized with $\mathrm{TiO}_{2}$. The efficiency for this system can reach 5.32\% [20].

\subsection{CdS nanorods}

CdS nanorods can be grown by hydrothermal process, where the nanoparticles used as seeds are electrochemically deposited. An example of this process is provided by Chen et al. [24] who fabricated $\mathrm{CdS}$ nanostructures for optical and electrical devices. They obtained $\mathrm{CdS}$ nanorod arrays with various shapes and sizes with a wide band gap absorption of light. $\mathrm{CdS}$ nanorod structures are used in HSC due to their capability to improve the power conversion efficiency in solar cells. HSC nanostructured device obtained 
by Chen et al. [24] consisted of a layered structure with the following sequence: ITO/CdS nanorod arrays/MEH-PPV/Au. The CdS nanoparticle layer that acts as seed layer was obtained by electrodeposition directly on ITO. CdS nanorods obtained by hydrothermal process had a hexagonal structure and sizes from $10 \mathrm{~nm}$ to $150 \mathrm{~nm}$ [24]. The photoluminescence of CdS nanorod arrays depends on the reaction temperature. The band-edge of $\mathrm{CdS}$ nanorod array decreases with increasing the temperature from $10 \mathrm{~K}$ to $300 \mathrm{~K}$. The power conversion efficiency in this particular device $\mathrm{ITO} / \mathrm{CdS}$ nanorod arrays/MEH-PPV/Au was $0.34 \% \pm 0.06 \%$ and the thickness MEH - PPV layer was about $350 \mathrm{~nm}$ [24].

\section{6. $\mathrm{ZnO}$ Nanostructures}

$\mathrm{ZnO}$ has a large band gap of $3.37 \mathrm{eV}$ and it is used in HSC as an alternative to other oxides to ensure a better open-circuit photovoltage. Among various techniques developed to produce $\mathrm{ZnO}$ nanostructures, electrochemistry is one of the techniques that offers innovative approaches to produce complex nanostructures with interesting properties.

ZnO nanorods: Rusen et al. [25] obtained a coreshell hybrid nanomaterial by electrodepositing $\mathrm{ZnO}$ nanorods over an electroconductive material with a photonic crystal structure (PC). The $\mathrm{ZnO}$ nanorods electrodeposited on hybrid the $\mathrm{Cu} /$ polymer core-shell structure had diameters of 50-100 nm and lengths of about 300-350 nm [25]. Another example was demonstrated by Chang et al. [26]. They fabricated films of $\mathrm{ZnO}$ nanoparticles array as seeds using self-assembled polymeric hollow particles over ITO using hydrothermal method. The $\mathrm{ZnO}$ nanorods had hexagonal shape, with a diameter between $50 \mathrm{~nm}$ and $100 \mathrm{~nm}$, a deviation of $\pm 80 \mathrm{~nm}$, and arranged in an array. $\mathrm{ZnO}$ array films were prepared in various growth conditions with wavelengths of about $400 \mathrm{~nm}$ to $1000 \mathrm{~nm}$ [26].

ZnO nanowires: Vapor-liquid-solid (VLS) is the main techniques to grow semiconductor nanowires. The growth of one-dimensional structures involves the presence of a seed that melts, forming a catalytic liquid alloy. The liquid -solid interface is the place where nucleation occurs, while the adsorption of gas happens at the liquid-vapor interface, supersaturating the liquid alloy. The nanowires develop by a continuous nucleation and growth at the liquid-solid interface [27]. $\mathrm{ZnO}$ nanowire [28] for dye-sensitized solar cells (DSSC) were grown by VLS. The $\mathrm{ZnO}$ nanowires with $130 \mathrm{~nm}$ in diameter were formed perpendicular to the $\mathrm{F}: \mathrm{SnO}_{2}$ (FTO) glass substrate. The efficiency of a ZnO NWs based DSSC device was between 1.2 and $1.5 \%$, while the efficiency of $\mathrm{TiO}_{2}$ NWs-based DSSC was 5-6\% [28].

\subsection{InP core - shell nanopillar}

Other photovoltaic cells (PV) such as arrays of InP nanopillars (NPL) were studied by Fan et al. who used metal organic vapor phase epitaxial method (MOVPE) and vapor-liquid-solid (VLS) [29]. This method results in $\mathrm{p}-\mathrm{n}$ InP core-shell nanopillars by growing first p-type InP on a substrate, followed by epitaxial growth of n-type InP layer. During the growth, $\mathrm{SiO}_{2}$ was introduced over p-type InP. The PV cell obtained using the p-n InP core - shell nanopillar array had a filling factor of about $27 \%$, and an efficiency of about 3.37\% [29].

\subsection{Ge nanopillar}

Another interesting example is a structure with dual-diameter nanopillar array, which was obtained by template synthesis in anodized aluminum oxide (AAO) membrane [29]. Ge nanopillars have a diameter by $60 \mathrm{~nm}$ at one end and adsorb the light at wavelengths between $450 \mathrm{~nm}$ and $900 \mathrm{~nm}$. The diameter at the base has $130 \mathrm{~nm}$ and adsorb the light at wavelengths between $300 \mathrm{~nm}$ and $900 \mathrm{~nm}$. The dual - diameter pillar array has a good optical absorption and efficiency close to $99 \%$ [28, 29].

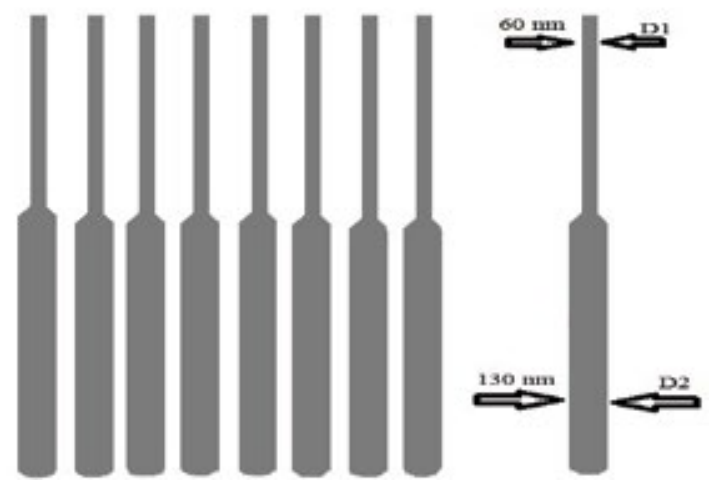

Figure 6 Illustration on Ge dual-diameter nanopillars that were grown in AAO [29]. 


\subsection{Nanotube and Nanocable Structures}

Template synthesis for nanotube and nanocable structures is mainly used in combination with electrochemical deposition. In this method, one side of a porous membrane is covered with a metal film that acts as a cathode in an electroplating system. Various membranes can be used, but the membranes with transversal pores are preferred such as polycarbonate track-etched membranes (PCTE) and anodized aluminum oxide (AAO). Martin et al. [32] first used $\mathrm{Au}$ tubes and an polymer polypyrrole with an template membrane as polycarbonate which has a diameter $10 \mathrm{~nm}$ with a pore densities about $10^{9}$ pore $/ \mathrm{cm}^{2}$, using electrochemical deposition [32].

Other remarkable example is a nanocable (core/shell) structure of $\mathrm{CdTe} / \mathrm{CdS}$ which was obtained by Vidu et al. [31] using template synthesis techniques. This $\mathrm{CdTe} / \mathrm{CdS}$ nanocable structure may provide higher efficiency than thin film configuration, and a total power output that is 1.5 to 3 times higher than current technologies. This columnar architecture (Figure 7) has high surface area, superior light trapping and minimizes the recombination of electrons due to the high spect ratio metalic core [30].

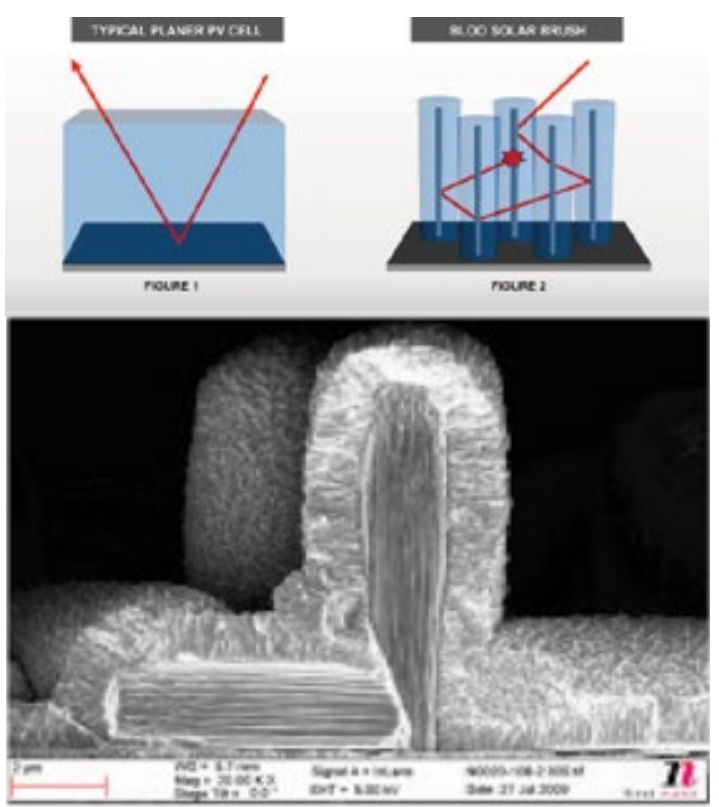

Figure 7. Nanocable (core - shell) structure of $\mathrm{CdTe} / \mathrm{CdS}$ for the 3D generation solar cells [R. Vidu].

\subsection{Carbon nanotube}

Carbon nanotube (CNT) [32] may be used in solar cells fabrication, where they replace the ITO glass substrate using a roll-to-roll printing process to decrease the cost of manufacturing. An example is the use of single wall carbon nanotube (SWNTs) in a film for anode, and a bulk - heterojunction (BHT) PEDOT: PSS for HSC device [32]. The SWNTs was used with an PEDOT: PSS polymer and has a PCE of $2.5 \%$ [32]. It was also used as electrode in solar cell dye sensitized or organic solar cells.

\section{Nanoparticles for HSC}

Based on the efficiency data available in the literature for $\mathrm{HSC}$, Figure 8 was generated to correlate the shape of nanoparticles use in HSC and conversion efficiency. The highest performance was obtained for CIGS nanowires based solar cell produced by template synthesis with an efficiency of $6.18 \%$. HSC dye - sensitized solar cells based on $\mathrm{TiO}_{2}$ quantum dot (QD) shows an efficiency of $5.32 \%$ compared to nanotube $(4.24 \%)$ and nanowires $(6 \%)$. The lowest efficiencies were obtained for HSC made with nanoparticles and nanorods of low aspect ratios.

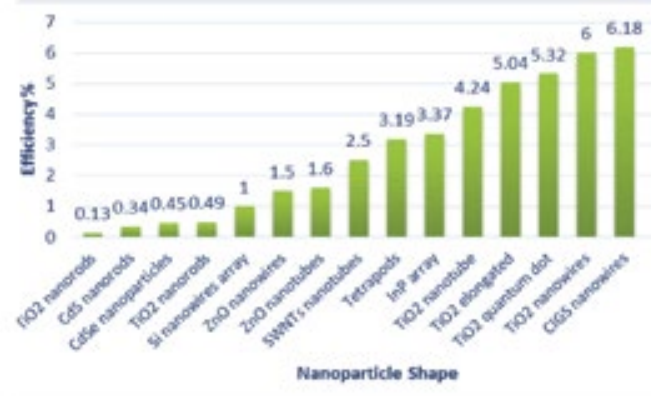

Figure 8. Efficiency of solar cells for various nanoparticle shapes

\section{Conclusions and perspectives}

Research community has recently devoted a lot of efforts to understand the relationship between synthesis of nanoparticles, their shape and size, and the efficiency of solar cells that uses them. Our study shows that the power conversion efficiency is affected by the form of nanoparticles, which represent the most important part of the hybrid device. Hybrid solar cells have a 
conversion efficiency of light into electricity rather low compared to $\mathrm{Si}$ and thin film cells, but have a higher efficiency than organic cells. In addition, they have the great advantage of being not expensive and to be produced by roll-to-roll printing method. These benefits bring the hybrid solar cells into the investor's attention and improvements in conversion efficiency is expected from HSCs in the near future, when high-aspect ratio nanoparticles are used in the design of cell architecture.

\section{Acknowledgement}

The work has been funded by the Sectorial Operational Programme Human Resources Development 2007-2013 of the Ministry of European Funds through the Financial Agreement POSDRU/159/1.5/S/132395.

\section{References}

1. A. J. Moule, C. Thambidurai, R Vidu, P.Stroeve, Hybrid solar cells: basic principles and the role of ligands. Materials Chemistry, 2012.

2. EREC, Renewable Energy Scenario to 2040. http://www.erec.org/fileadmin/erec docs/Documents/Pu blications/EREC Scenario 2040.pdf

3. www.e-solare.com/produse/schott-220w-poly

4. www.cheso.ro/invertoare-solare-power-one-aurorapvi.php.

5. Solarmer, http://www.solarmer.com/about opv.html. 6. Badea, A., Plus Energy Houses -Politehnica Plus Energy Building. 5th International Conference on Energy and Environment, CIEM 2011, Bucharest, 2011, 2011.

7. NREL, Improving PbS QD Solar Cell Power Conversion Efficiency to an NREL-Certified 4.4\%. 2012. 8. Tang, J., et al., Colloidal-QD PVs using atomic-ligand passivation. Nat Mater, 2011. 10(10): p. 765-71.

9. Laurentiu Fara, M.R. et al. "Fizica si tehnologia celulelor solare si sistemelor Fotovoltaice". Academiei Oamenilor de stiinta din Romania, 2009: p. 80-81. 10. Lazaro A. P. et al, Carrier Multiplication in Semiconductor Nanocrystals: Influence of Size, Shape, and Composition. American Chemical Society, 2013. 11. Kruszynska, M., et al., Synthesis and Shape Control of CuInS2 Nanoparticles. Journal of the American Chemical Society, 2010. 132(45): p. 15976-15986. 12. J.E.Brandenburg, et al., Influence of particle size in hybrid solar cells composed of CdSe nanocrystals and poly (3-hexylthiophene). PHYSICS, 2011. 110.

13. Farva, U. et al, Colloidal synthesis and air-annealing of CdSe nanorods. Mat Lett, 2010, 64(13) 1415. 14. Manna, L., et al., Controlled growth of tetrapod- branched inorganic NC. Nat Mater, 2003. 2(6): p. 382-5. 15. Bierman, M.J. and S. Jin, Potential applications of hierarchical branching nanowires in solar energy conversion. En \& Envir Sci, 2009. 2(10): p. 1050-1059. 16. Lechmann, M.C., et al., Comparison of Hybrid Blends for Solar Cell. Energies, 2010. 3(3): p. 301 17. CJGWS, B., "Sol-gel : Science: The Physics and Chemistry of Sol-Gel Processing.". Acad Press, 1990. 18. Noshin Mir, M.S.-N., Effect of tertiary amines on the synthesis and photovoltaic properties of TiO2 nanoparticles in dye sensitized solar cells. Electrochimica Acta, 2013. 102: p. (274-281). 19. Kamat, P.V., Quantum Dot Solar Cells. The Next Big Thing in PVs. J.Phys Chem Letts, 2013. 4(6): p. 908-918. 20. Halim, M.A., Harnessing Sun's Energy with Quantum Dots Based Next Generation Solar Cell. Nnanomaterials., 2012.

21. Thomas Dittrich n, A., AhmedEnnaoui, Concepts of inorganic solid-state nanostructured solar cells. Solar EnergyMaterials\&SolarCells, 2011.

22. Wei Zou et al., Fabrication of surface-modified CdSe quantum dots by self-assembly of a functionalizable comb polymer. Society of Chemical Industry, 2010. 23. Kusum Kumari et al, Effect of surface passivating ligand on structural and optoelectronic properties of polymer, J Physics D, Applied Physics, 2008.

24. Chen, F., et al., Large-scale fabrication of CdS nanorod arrays on transparent conductive substrates, Solar Energy, 2011. 85(9): p. 2122.

25. Rusen, E., A. Mocanu, and R. Somoghi, Core-shell hybrid material for $\mathrm{ZnO}$ nanorods generation. Colloid and Polymer Science, 2012. 290(18): p. 1937-1942. 26. Chang, C.-J. et al, Light-trapping effects and dye adsorption of $\mathrm{ZnO}$ hemisphere-array surface containing growth-hindered nanorods. Coll \& Surfaces 2010, 363(1-3): p. 22-29.

27. Joshi, R.K. et al, Assembly of one dimensional inorganic nanostructures into functional $2 D$ and $3 D$ architectures. Synthesis, arrangement and functionality. Chemical Society Reviews, 2012. 41(15): p. 5285-5312. 28. Yu, M., et al., Recent advances in solar cells based on 1 D nanostructure arrays. Nanoscale, 2012. 4(9):2783 29. Rehan Kapadiaa, Z.F., KuniharuTakei, AliJaveya., Nanopillar photovoltaics:Materials,processes, and devices. www.elsevier.com/locate/nanoenergy, 2011. 30. Feng Gao, S.R.a.J.W., The renaissance of hybrid solar cells: progresses, challenges, and perspectives. Energy \& Environmental Science, 2020.

31. Ku, J.R., et al., Fabrication of nanocables by electrochemical deposition inside metal nanotubes. JACS, 2004. 126(46): p. 15022-15023.

32. Steve Park, M.V.a.Z.B., A review of fabrication and applications of carbon nanotube film-based flexible electronics. Nanoscale, 2012. 